\title{
Langerhans Cell Histiocytosis: Rare Disease Treated With Chemotherapy and Radiotherapy
}

\author{
Dr. Manjula Beck ${ }^{1}$,Dr.V B Rathore ${ }^{2}$,Prof V.Choudhary ${ }^{3}$,Prof S. K.Azad ${ }^{4}$, \\ Dr. P.Chandrakar ${ }^{5}$, Dr. Rajeev R Jain ${ }^{6}$,Dr. Madhu Verma ${ }^{7}$, Dr.Devvrat Hisikar ${ }^{8}$, \\ Dr. Rajendra Patel ${ }^{9}$, Dr.R M Chandola ${ }^{10}$, Mr S.K. Patnaikuni ${ }^{11}$, \\ Mr Ajay Taide ${ }^{12}$. \\ Department Of Radiotherapy, Pt J N M Medical College And Regional Cancer Centre Raipur (C.G.) India
}

\begin{abstract}
Langerhans Cell Histiocytosisrepresents a rare benign disorder previously designated as Histiocytosis X Varity” Type II Histiocytosis or Langerhans cell Granulomatosis, it occurs when the body accumulates too many immature langerhans cell a subset of the larger family of cell known as histocytes. Langerhans cell are of white blood cell that normally help the body to fight against infection. Langerhans cell histocytosis is most commonly characterized by single on multiple osteolytic bone lesion but also ulcerations of skin \& soft tissue and also involvement of the CNS. Bones are the most common localization of disease (40$78 \%$ ). Surgery is the treatment of choice in limited form of histiocytosis but in diffuse form only chemotherapy is used. The most of researches also recommends the radiotherapy in conditions, like Recurrence or progression of disease bone pain, exopthalmus, non surgical local changes. The aim of this study is to present four such rare patients having multi system diseases with multiple organs system treated with chemotherapy \& radiotherapy at our institution.
\end{abstract}

Keywords: Benign, chemotherapy, eosinophilic granuloma, multifocal lesion.

\section{Introduction}

Langerhans cell histiocytosis (LCH) is a rare benign histiocytoic disorder most commonly characterized by single or multiple osteolytic bone lesions but also ulcerations of skin and soft tissues and also involvement of the CNS are described. It is characterized by an uncontrolled clonal proliferation of langerhans cells which belong to the normal human mononuclear phagocytic system. Langerhans cell histiocytosis (LCH) formerly referred to as histiocytosis X, can be divided into three categories: eoisnophilic granuloma, Hand Schuller Christian disease and Abt_Letterer-Siwe disease. LCH involves single (single-system disease) or multiple (multiple-System disease) organ systems. In $60 \%$ bony manifestations as single-system disease with uni or multifocal lesions are present but also in multi-system disease with activity in other organ systems are also described. In case of involvement of the CNS diabetes insipidus is a typical symptom. Patients with single system disease tend do well. Patients with multiple system disease sometimes have an unpredictable outcome. Patients with only one bony lesion progression, disseminated disease and fatal outcome has been described. Nevertheless some self healing and self limiting courses has been reported.

\section{Material Methods}

We are presenting such rare disease of Langerhans histiocytosis who attended our OPD at Regional cancer Centre Raipur Chhattisgarh. Our study includes four patients with isolated and those with multifocal bone lesion treated with chemotherapy and Radiotherapy. The aim of our study is to find out disease free survival, recurrent disease death and therapy related side effects of chemotherapy \& Radiotherapy. According to the LCH classification of Greenberger et al two child were having stage III disease \& two adult having stage II disease.

Table 1: Clinical Presentation

\begin{tabular}{|l|l|l|}
\hline S.No. & Age & Presentation \\
\hline 1 & $<1 \mathrm{Y}$ & Multiple bone lesion of long femur bone \\
\hline 2 & $2 \mathrm{Y}$ & $\begin{array}{l}\text { Lesion in the oral mucosa, gums, palatal bone with skin } \\
\text { involvement }\end{array}$ \\
\hline 3 & $21 \mathrm{Y}$ & $\begin{array}{l}\text { Craniofacial bone involvement with lesion in the orbital soft tissue } \\
\text { extension }\end{array}$ \\
\hline 4 & $16 \mathrm{Y}$ & Eye involvement with proptosis. Lesions in the orbit \\
\hline
\end{tabular}




\section{Treatment Given}

1. Chemotherapy Inj. Viblastin, Tab. Prednisolone- Weekly for 8 weeks.

2. Chemotherapy Inj. Vinblastin, Tab. Prednisolone weekly for 6 wks.

3. Chemotherapy + RT- weekly 12 wks Inj. Vinblastin + Radiotherapy with linac $2400 \mathrm{cg} /$ vinblastine 12\#/tocranial bone+Maintaince therapy crossing of pulses of Inj. Vinblastin \& Tab. Prednisolone.

4. Chemotherapy 1 cycle of Inj.Vinblastin + Tab. Prednislone then lost to treatment.

\section{Results And Discussion}

In accordance with the nature of $\mathrm{LCH}$ all three patient were having NAD (Non Active disease) with regressive disease having regression of sign and symptoms with no new lesions. The patients are advised for 12 month pulse therapy of maintenance and thereafter advised for the follow up investigation after and therapy. For clinical exam every 6 weeks for 1 year then every 3 monts for one year and 6monthly for next 2 years. Similarly height, weight and pubertal status every 6 month for 5years. Patients were kept on follow up with Radiographs of some lesion only if new lesion or reactivations are suspected.

\section{Conclusions}

Due to rarity of LCH and the variety of symptoms of the disease, oncologist encounters a number of diagnostic and therapeutic difficulties Chemotherapy and Radiotherapy is a safe and effective treatment option for patient suffering from LCH Chemotherapy for the multifocal lesion. Low RT dose to unifocal lesion shows sufficient local control. Side effect are low and no treatment related deaths were observed.

\section{References}

[1]. Martínez-Pereda C, Guerrero-Rodríguez V, Guisado-Moya B, Meniz-García C. Langerhans cell Madrigal histiocytosis: Literature review and descriptive analysis of oral manifestations. Med Oral Patol Oral Cir Bucal.2009;14:E222-8. [PubMed]

[2]. Greenberger JS, Crocker AC, Vawter G, Jaffe N, Cassady JR. Results of treatment of 127 patients with systemic histiocytosis. Medicine (Baltimore) 1981;60:311-38. [PubMed]

[3]. Jonas N, Mulwafu W, Khosa SA, Hendricks M. Case study: Langerhan's cell histiocytosis (LCH) Int J Pediatr Otorhinolaryngol. 2008;3:61-5.

[4]. Yashoda-Devi B, Rakesh N, Agarwal M. Langerhans cell histiocytosis with oral manifestations: A rare and unusual case report. J Clin Exp Dent. 2012;4:e252-5. [PMC free article] [PubMed]

[5]. Shevale VV, Ekta K, Snehal T, Geetanjal M. A rare occurrence of Langerhans cell histiocytosis in an adult. J Oral Maxillofac Pathol. 2014;18:415-9. [PMC free article] [PubMed]

[6]. Aruna DR, Pushpalatha G, Galgali S, Prashanthy Langerhans cell histiocytosis. J Indian Soc Periodontol.2011;15:276-9. [PMC free article] [PubMed]

[7]. Tesluk EW, Szutkowski Z, Kawecki A. Langerhans cell histiocytosis of bone - A case report and review of literature. J Oncol. 2003;53:161-4.I

[8]. Divya KS. Oral manifestion of Langerhans cell histiocytosis mimicking inflammation. Indian J Dent Res.2014;25:22830. [PubMed]

[9]. Neville BW, Damm DD, Allen CM, Bouquot JE. Oral and Maxillofacial Pathology. Ch. 13. Vol. 2. New Delhi: Reed Elsevier India Pvt. Ltd; 2004. Langerhans cell histiocytosis. Hematological disorders; pp. 513

[10]. Lajolo C, Campisi G, Deli G, Littarru C, Guiglia R, Giuliani M. Langerhans's cell histiocytosis in old subjects: Two rare case reports and review of the literature. Gerodontology. 2012;29:e1207-14. [PubMed]. 